\title{
Catabolism of human serum IgG in health, rheumatoid arthritis, and active tuberculous disease
}

\section{Possible influence of IgG structure}

\author{
JOHN WATKINS AND A. J. SWANNELL \\ MRC Rheumatism Research Unit, Canadian Red Cross Memorial Hospital, Taplow, Maidenhead, Berkshire
}

Probably all macromolecules, whether naturally occurring or synthetic, are subject to ageing phenomena. The random movements of long flexible chains must inevitably end in rigid tangled configurations. Aged, denatured, or aggregated proteins in serum will no longer be able to carry out their predetermined functions and mechanisms must exist for their removal.

The catabolic mechanism for serum proteins is probably initiated by recognition of the denatured molecule. A fault in this recognition might have serious pathological consequences for the individual concerned, especially when serum immunoglobulins are involved, since the participation of these proteins in the formation of immune complexes has given them a possible pathogenic role in diseases such as rheumatoid arthritis(RA). Abnormal rates of IgG elimination may be related to basic immunological mechanisms in rheumatoid arthritis and, if this is so, then catabolic studies may provide an additional means for the characterization of the disease. A study has been made of the catabolism of iodine-labelled serum IgG in health, rheumatoid arthritis, and active tuberculous disease to investigate this possibility.

\section{Methods}

Immunologically pure IgG was isolated from the serum of five healthy individuals, six rheumatoid patients, and four patients with active tuberculous disease, by column chromatography on DEAE-cellulose (DE52, Whatman Limited, Maidstone, Kent) with $0.01 \mathrm{M}$ phosphate buffer, $\mathrm{pH}$ 6.2. Each immunoglobulin preparation was labelled (McFarlane, 1958) with iodine-125, and the autologous preparation ( $20 \mathrm{mg}$. IgG; $50 \mu \mathrm{Ci}$ ) was injected intravenously into the individual concerned. Sodium iodide $(40 \mathrm{mg}$ ) was administered daily to block thyroid uptake of radioactivity. Elimination of the labelled protein was followed by scintillation counting of serum samples at intervals of 2 to 3 days for a period of 32 days.

\section{Calculation of biological half-life values}

Radiation levels were measured on all the serum samples at the end of each catabolic experiment. Errors arising from isotope decay were thus eliminated. Background radiation corrections were negligible and in any case less than the error ( $\leqslant 5$ per cent.) on individual serum measurements. Individual measurements were plotted against time on 2-cycle logarithm paper and the best visual curve fitted to these points. Half-life values were measured from the final slope of these graphs, terminating at 32 days.

\section{Measurement of serum IgG levels}

IgG levels were measured on serum samples taken for IgG preparations by the technique of radial immunodiffusion on cellulose acetate membranes (Vergani, Stablini and Agostoni, 1967). Goat anti-human IgG antisera and IgG serum standards were obtained commercially (Hyland, Baxter Laboratories, Norfolk, England).

\section{Patients and volunteers (Table, overleaf)}

The five healthy individuals (Cases 7-11) were members of the laboratory staff. The six rheumatoid patients (Cases 1-6) all suffered from seropositive RA (American Rheumatism Association, 1959). Four (Cases 3-6) had active disease as judged by the amount of morning stiffness, number of joints involved, associated soft tissue swelling, limitation of joint movement, and raised erythrocyte sedimentation rate (ESR). They were not receiving gold or corticosteroid therapy.

The four patients (Cases 12-15) with tuberculosis had signs of active disease. Two (Cases 12 and 15) had pulmonary tuberculous disease without pleural effusions and two (13 and 14) had tuberculous cervical nodes.

\section{Results}

Serum IgG elimination curves in health show differences in degree of curvature (Fig. 1, overleaf). The curved pattern, indicating heterogeneous catabolism, can be explained to some extent as the resultant of 
Table Biological half-life and serum concentration of IgG in arthritic patients, healthy subjects, and tuberculous patients

\begin{tabular}{|c|c|c|c|c|c|}
\hline \multirow[t]{2}{*}{ Diagnosis } & \multirow{2}{*}{$\begin{array}{l}\text { Case } \\
\text { no. }\end{array}$} & \multirow[t]{2}{*}{ Sex } & \multirow{2}{*}{$\begin{array}{l}\text { Age } \\
\text { (yrs) }\end{array}$} & \multicolumn{2}{|c|}{ Immunoglobulin $G$} \\
\hline & & & & $\begin{array}{l}\text { Half-life* } \\
\text { (days) }\end{array}$ & $\begin{array}{l}\text { Serum concentration } \\
(\mathrm{mg} . / 100 \mathrm{ml} .)\end{array}$ \\
\hline Rheumatoid arthritis & $\begin{array}{r}1 \\
2 \\
+3 \\
\dagger 4 \\
\dagger 5 \\
\dagger 6\end{array}$ & $\begin{array}{l}\mathbf{F} \\
\mathbf{M} \\
\mathbf{F} \\
\mathbf{M} \\
\mathbf{F} \\
\mathbf{M}\end{array}$ & $\begin{array}{l}42 \\
32 \\
50 \\
65 \\
35 \\
59\end{array}$ & $\begin{array}{l}20 \\
22 \\
12 \\
13 \\
14 \\
14\end{array}$ & $\begin{array}{r}1034 \\
803 \\
900 \\
1430 \\
1551 \\
1265\end{array}$ \\
\hline Healthy & $7-11$ & $\begin{array}{l}3 \mathrm{~F} \\
2 \mathrm{M}\end{array}$ & $21-48$ & $19-24$ & $902-1210$ \\
\hline Tuberculosis & $\begin{array}{l}12 \\
13 \\
14 \\
15\end{array}$ & $\begin{array}{l}\mathbf{M} \\
\mathbf{M} \\
\mathbf{M} \\
\mathbf{M}\end{array}$ & $\begin{array}{l}38 \\
35 \\
64 \\
35\end{array}$ & $\begin{array}{l}17 \\
15 \\
18 \\
17\end{array}$ & $\begin{array}{r}1837 \\
1353 \\
>2200 \\
>2200\end{array}$ \\
\hline
\end{tabular}

* Terminal half-life measured over 32 days after equilibration of tracer IgG between intravascular and extravascular pools. $\dagger$ Patients with active disease.

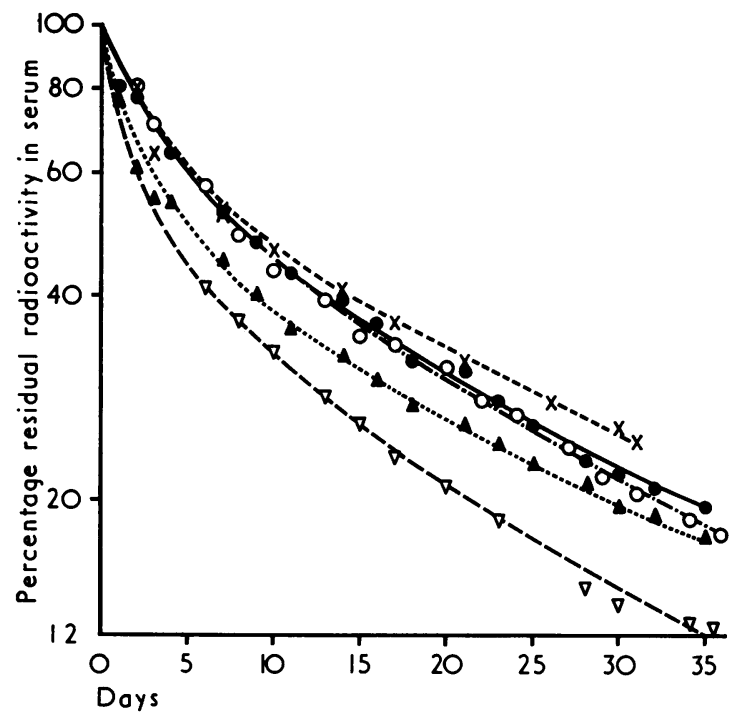

FIG. 1 Serum IgG elimination patterns measured in five healthy individuals

mixtures of $\gamma \mathrm{G} 1$ and $\gamma \mathrm{G} 2$ subclass proteins, each breaking down at a characteristic rate (Watkins and Tee, 1970).

Typical serum IgG elimination curves in health, RA (active and inactive), and tuberculous disease are contrasted in Fig. 2. The catabolic data for all individuals is summarized in the Table. The four RA patients with active disease have a greatly increased catabolic rate for their IgG (T⿺ $\frac{1}{2}=12$ to 14 days) as compared with the two patients with inactive disease. The latter had a biological half-life similar to that found for the five healthy subjects $\left(T \frac{1}{2}=19\right.$ to 24

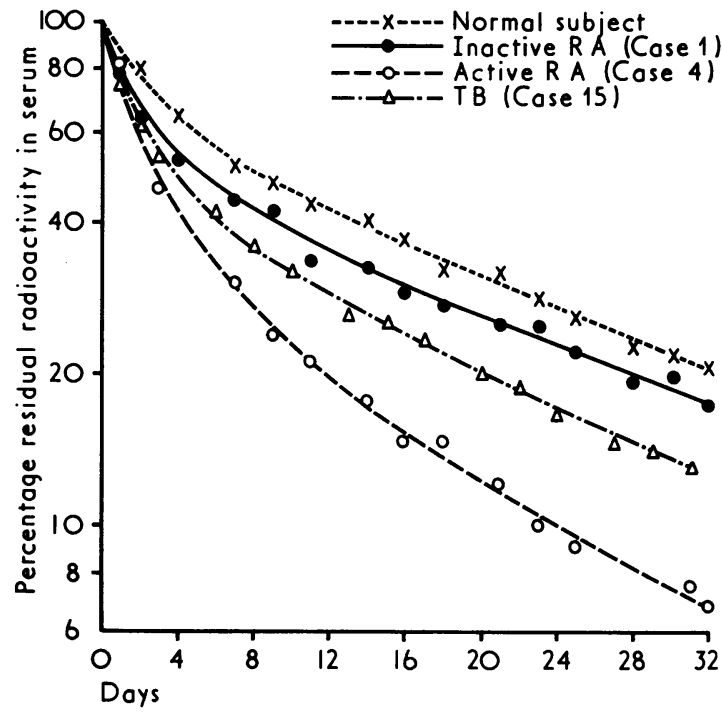

FIG. 2 A comparison of typical serum IgG elimination patterns in health, rheumatoid arthritis, and tuberculous disease. The individuals concerned are identified by numbers (see Table)

days). There was no apparent correlation between duration of disease and half-life value in the rheumatoid patients. The patients with tuberculosis show a rate of IgG catabolism intermediate (T $\frac{1}{2}=15$ to 17 days) between that of health and of active rheumatoid disease.

There was no direct correlation between the serum IgG level and its rate of catabolism (Fahey and Robinson, 1963; Levy, Barnett, MacDonald, and Klinenberg, 1970). Indeed, the IgG levels in the TB patients are considerably higher than those of the RA patients (Table). 


\section{Discussion}

Our studies on serum IgG elimination in normal health suggest that individuals vary considerably in their ability to recognize molecular configuration, both at the primary level, distinguishing IgG subclasses (Watkins and Tee, 1970), and in distinguishing variations in tertiary molecular structures. Such variations in tertiary structures appear to occur during active antibody production, since IgG preparations containing freshly produced specific antibodies (to tetanus toxoid) were shown to be catabolized at a significantly faster rate than control IgG when compared simultaneously in a healthy individual (Watkins and Tee, 1970). We have reported similar findings in mice. (Tee, Watkins, and Wang, 1965).

The slightly increased catabolic rates observed in the TB patients may indicate, therefore, the more rapid elimination of newly formed antibody IgG: either antibodies specific to the tubercle bacillus or antibodies associated with prolonged infection. The high serum IgG concentrations measured in the tuberculous patients (Table) would certainly indicate an immune response.

Several workers (Levy and others, 1970; Vaughan, Armato, Goldthwait, Brachman, Favour, and Bayles, 1955; Andersen and Jensen, 1965) have reported increased rates of serum IgG catabolism in patients with RA and it has been suggested that these patients may possess enhanced immunological mechanisms for the removal of denatured IgG (Vaughan and others, 1955).

Possible effects of drugs, particularly corticosteroids, administered to rheumatoid patients cannot be disregarded when evaluating catabolic data although this factor is frequently overlooked in the literature. We have excluded patients receiving corticosteroids from our investigations, but still have found a significantly increased rate of IgG catabolism in four out of six rheumatoid patients investigated. The results indicate that increased rates of catabolism may be associated only with active disease.

It is interesting to speculate on the mechanism of the elimination of denatured immunoglobulin molecules. Two mechanisms may be involved, one predominantly biochemical or enzymatic, the other involving immunologically competent cells. The latter would be unlikely to play a significant role in normal health since they could produce autoantibodies.

The enzymatic elimination mechanism may be similar to that proposed by Brambell (1966); fixation to cell receptor sites of structures exposed on the molecule by the ageing process and subsequent scission of the bound molecule by intracellular proteases. Its rate determining step would be the efficiency of recognition, or of binding, of the denatured molecules by the receptor sites. This would give rise to variations in rates of catabolism between individuals. If, however, the denatured molecules are removed too slowly, then they may form soluble aggregates which accumulate in the vascular bed. There is evidence for the presence of appreciable quantities of such denatured IgG molecules in the serum of patients with rheumatoid arthritis (Watkins and Tee, 1971). Grossly aggregated IgG may be cleared rapidly from the circulation by macrophage activity: it is likely to possess the physiological activity of immune complexes (Brown, Schwab, and Holborow, 1970) and it may stimulate the range of antiglobulin antibodies seen in rheumatoid patients.

\section{Summary}

The catabolism of serum IgG was studied in five healthy volunteers, six patients with rheumatoid arthritis, and four patients with active tuberculous disease. A greatly increased rate of catabolism was observed in the four rheumatoid patients with active disease ( $T \frac{1}{2}=12$ to 14 days) as compared with the healthy controls ( $T \frac{1}{2}=19$ to 24 days). The patients with tuberculous disease showed an intermediate rate of catabolism ( $\mathrm{T} \frac{1}{2}=15$ to 17 days).

It is suggested that the differences in individual rates of IgG elimination reflect degrees of recognition of the molecular structure of this protein.

\section{References}

American Rheumatism Association (1959) Ann. rheum. Dis., 18, 49 (Diagnostic criteria for rheumatoid arthritis, 1958 revision)

ANDERSEN, S. B. AND Jensen, K. B. (1965) Clin. Sci., 29, 533 (Metabolism of $\gamma$ G-globulin in collagen disease)

Brambell, F. W. R. (1966) Lancet, 2, 1087 (The transmission of immunity from mother to young and the catabolism of immunoglobulins)

Brown, J. C., Schwab, J. H., AND Holborow, E. J. (1970) Immunology, 19, 401 (The localization of immunoglobulin and immune complexes in lymphoid tissue)

FAHEY, J. L., AND Robinson, A. G. (1963) J. exp. Med., 118, 845 (Factors controlling serum $\gamma$-globulin concentration)

LeVY, J., BARnetT, E. V., MAcDonald, N. S., AND KlinenberG, J. R. (1970) J. clin. Invest., 49, 708 (Altered immunoglobulin metabolism in systemic lupus erythematosus and rheumatoid arthritis)

MCFARLANE, A. S. (1958) Nature (Lond), 182, 53 (Efficient trace-labelling of proteins with iodine)

TeE, D. E. H., WATKINS, J., AND WANG, M. (1965) Ibid., 208, 251 (Breakdown rate of serum 7S $\gamma$-globulins in mice) 
Vaughan, J. H., Armato, A., Goldthwait, J. C., Brachman, P., Favour, C. B., and Bayles, T. B. (1955) J. clin. Invest., 34, 75 (A study of gamma globulin in rheumatoid arthritis)

Vergani, C., Stabilini, R. ANd Agostoni, A. (1967) Immunochemistry, 4, 233 (Quantitative determination of serum immunoglobulins by single radial immunodiffusion on cellulose acetate)

Watkins, J., AND Swannell, A. J. (1972) Ann. rheum. Dis., 31, 218 (Enhanced catabolic rate and a structural anomaly in the serum IgG of RA patients) AND TEE, D. E. H. (1970) Immunology, 18, 537 (Catabolism of $\gamma$ G-globulin and myeloma proteins of the subclasses $\gamma \mathbf{G}_{1}$ and $\gamma \mathbf{G}_{2}$ in a healthy volunteer)

- _- (1971) Biochem. J., 122, 33P (Patterns of serum $\gamma \mathrm{G}$-globulin heterogeneity in health, rheumatoid arthritis and cancer) 